\title{
Comparison of Post-Operative Pain After Laparoscopic Cholecystectomy with the Use of Fentanilo or Sufentanilo
}

\author{
David Alejandro Jurado Mendoza MD ${ }^{1}$, Carlos barrientos Anderwald MD ${ }^{1}$, Ana \\ PrixilaGonzález $\mathrm{MD}^{2}$, Luis Angel Medina Andrade $\mathrm{MD}^{3 *}$, Patricia Becerril Rico $\mathrm{MD}^{4}$, \\ Alberto Robles Méndez Hernández MD ${ }^{1}$, Haizel Valencia Romero MD $^{3}$, Mariel Andrea Del \\ Rio Parra MD ${ }^{1}$, Sara Gabriela Gonzalez Sanchez MD ${ }^{1}$, Paola Guadalupe Villatoro Portillo \\ $\mathrm{MD}^{1}$, Jesús Armando Nochebuena López $\mathrm{MD}^{1}$, Fatima Careli Morado Manriquez $\mathrm{MD}^{\mathbf{1}}$ \\ ${ }^{1}$ Anesthesiology Service, Facultad Mexicana de Medicina, Universidad La Salle México, Hospital Ángeles \\ Metropolitano, Ciudad de México, México \\ ${ }^{2}$ Colon and retum, Hospital Angles Metropolitano, Ciudad de México, México \\ ${ }^{3}$ General Surgery Service, Hospital General de Zona \#30, IMSS, México City, México \\ ${ }^{4}$ Anesthesiology service, Hospital General $1^{\circ}$ de Octubre, ISSSTE, México City, México
}

*Corresponding Author: Luis Angel Medina Andrade MD, General Surgery Service, Hospital General de Zona \#30 IMSS, Mexico City, Mexico, Email: buismedina_5@hotmail.com

\begin{abstract}
Objective: To compare the postoperative analgesic effect, in patients with laparoscopic cholecystectomy under general anesthesia, in which fentanilo vs sufentanilo were used.

Material and methods: It was a randomized clinical trial from November 2016 to March 2017 in the Hospital Ángeles Metropolitano. A total of 50 patients that underwent laparoscopic cholecystectomy under general anesthesia were included for analysis and divided in two groups: Group 1 was treated with fentanilo for induction at doses of 3-5 mcg/ $\mathrm{kg}$, and maintenance doses of 50-100 mcg every 30 minutes; Group 2: was treated with sufentanilo at doses of 10-15 mcg for induction, and maintenance doses of $10 \mathrm{mcg}$ every 60 minutes. The analgesic effect was analyzed by hemodynamic stability, cardiac frequency changes and arterial blood pressure, and finally visual pain analogue scale.
\end{abstract}

Results: Two groups were analyzed, 1 (fentanilo) and 2(sufentanilo) of 25 patients each one, data about mild, moderate or severe pain was collected at post-operative recovery room incoming, 1 hour, 12 hours and 24 hours after surgery. The incidence and intensity of pain was similar in both groups, without a significant difference, the pain at 12 hours after surgery was higher in both groups although not significant $(p<0.05)$.

Conclusion: The postoperative analgesia with diminished doses of sufentanilo during laparoscopic cholecystectomy does not present a real advantage compared with the use of fentanilo in the present study, and present equivalent use of postoperative analgesics. More studies and a bigger sample are needed for a correct comparison of this two drugs in laparoscopic cholecystectomy.

Keywords: fentanilo, sufentanilo, laparoscopica cholecystectomy, analgesia

\section{INTRODUCTION}

There are many postoperative analgesic techniques for laparoscopic surgery, although there no existing gold standard for the use in multiple laparoscopic procedures.

Pain is a complex sensation and challenging to deal with, according to their multifactorial origin, and with the capacity to change the pain systems of transmission and modulation, and be accompanied by another systemic alteration increasing the morbidity and mortality associated. The pain is defined as a sensation and discomfort emotional experience, in response to a tissue alteration, real or only potential. It constitutes an alarm signal that protects the organism, with the objective of reducing the cause and limit the consequences; in this case, the term is called nociception.

\subsection{Physiopathology of Pain in Laparoscopic Surgery}

Nociceptive stimuli are transmitted from the periphery to the spinal cord through the 
peripheral nerves, which are formed by fibers of three types (A, B, and $\mathrm{C}$ ), all of which are formed by myelinated fibers linked to somatic sensations. It has been considered that both the A-delta and $\mathrm{C}$ fibers are directly responsible for the conduction of pain; these primary afferent fibers establish their first relay at the level of the spinal cord to the spinal cord that reaches through posterior roots. The painful stimulus that travels through the fibers A-delta and C releases excitatory neurostimulators such as glutamate, aspartate, and substance $\mathrm{P}$ upon reaching the spinal cord causing calcium to enter the cell to stimulate the NMDA (Nmethyl) excitatory receptors D aspartate), neuroquinines and phosphocytokines.

There are a number of biochemical receptors that cover the membrane of afferent fibers; some of them are transducers, that is, capable of transforming a physical stimulus into a current that depolarizes the membrane. Often, these elementary transducers are specific; among them is the super family of sodium channels blocked by amiloride, called acid-sensitive ion channels (ASIC); these are activated when the $\mathrm{Ph}$ decreases to 6.9 , the $\mathrm{Ph}$ of the inflamed tissues may decrease to 5.5, which means that the activation of these receptors accompanied the smallest inflammatory phenomenon.

Tissue injury caused by tissue distraction or traction determines the release of ATP and hydrogen ions, the only excitatory substances strictly; Hydrogen ions activate the ASIC 1 receptor resulting in the activation of the catatonic channels, which depolarize the free terminations of the fiber; Some activators of this type of receptors are carbonic acid and lactic acid. By being depolarized from cationic calcium channels linked to a high threshold voltage, they allow calcium ions to enter neurons after depolarization and, therefore, can influence synaptic receptor and mediator systems, thus excitability levels of the membrane.

\subsection{Fentanil}

It is the synthetic opioid most used in Mexico in all types of procedures since its degree has excellent versatility concerning different routes of administration; however, its pharmacokinetic profile is not the most indicated for continuous intravenous infusion, due to the broad sensitive context of life average that it has (7). Synthesized by Paul Jansen, and introduced to clinical practice by Joris de Castro, it belongs to the family of 4 anilinopiperidines, it is 80 to 100 times more potent than morphine, it binds strongly to acidic glycoprotein, due to its high liposolubility to Physiological $\mathrm{pH}$, is widely distributed in organs and tissues, reaching high concentrations in well-perfused organs after intravenous administration. It is mainly metabolized by $\mathrm{N}$ dealkylation to norfentanyl. For practical purposes, it is considered that the clearance is hepatic, being able to be between $0.3 \mathrm{~L} / \mathrm{min}$ up to $1.2 \mathrm{~L} / \mathrm{min}$, always keeping in mind the perioperative and individual influences according to the physical state of the patient (8).

\subsection{Sufentanil}

Phenylpiperidine N- [4 - (methoxymethyl) -1 [2 - (2-thienyl) ethyl] -4-piperidinyl] -N-2hydroxy-1 phenylpropanoamide citrate: 2hydroxy-1, 2, 3-propanotricarboxylate, is 7 to 10 times more potent than fentanyl, with high affinity to the mu receptor and a slow dissociation of it. More than $90 \%$ of the drug binds to acid glycoprotein, representing a high binding compared to fentanyl, in addition to reaching a rapid compartmental equilibrium, favoring the low possibility of accumulation, having a sensitive context of lower half-life than fentanyl, which allows faster removal of the plasma compartment. The metabolism is hepatic through O-demethylation and $\mathrm{N}$ dealkylation, excreting inactive metabolites through urine and bile (9). The most used intraoperative opioids are morphine, fentanyl, sufentanil, remifentanil, and alfentanil, which are used daily in combination with other agents, analgesic or not, to improve their effectiveness or decrease their undesirable effects. The combination of an opioid with a second agent to produce a combination of opioid analgesics classified into six main categories: 1) Prolong the analgesic duration, 2) Improve or optimize analgesic efficacy (for example, analgesic synergy). 3) Reduce adverse effects; 4) Minimize opioid effects that are not beneficial (or conversely, increase the beneficial effects of opiates). 5) Reduce opioid tolerance / opioid-induced hyperalgesia, and 6) Combat dependence / addictive potential/feelings of anxiety $(10,11)$. The pharmacokinetic models of opioids are based on the physicochemical characteristics of each of them, and the analgesic effect is not easy to quantify, since a time relationship between the type of administration, based on its potency and efficacy, and in the interaction with other drugs (hypnotic, inhaled), there is always a delay between the administration of the dose via 
plasma until adequate concentrations are reached in the effector site, this compartment being already considered with a drug entry rate (ke1), an output of it (ke0), the time to reach the balance between the central compartment and the effect $(\mathrm{T} 1 / 2 \mathrm{ke} 0=\ln 2 / \mathrm{ke} 0)$, so it is possible to consider that with $3 \mathrm{~T} 1 / 2 \mathrm{Ke} 0$ $87.5 \%$ of the process is reached and with 5 halflives $97 \%$. The inverse relationship between the output constant of the effect compartment $(\mathrm{Ke} 0)$ and the half-life of the balance between the central and effect compartment (T1 / $2 \mathrm{ke} 0$ ), then at greater ke0, less T1 / 2 and the balance between plasma and effect is reached more quickly (11).

\section{MATERIAL AND MethodS}

A controlled clinical trial, experimental, longitudinal, prospective, comparative, causeeffect, simple blind, was performed under the following procedure: All patients admitted to the postoperative anesthesia area of laparoscopic cholecystectomy were included under general anesthesia at the Angeles Metropolitan Hospital with the following inclusion criteria: adult patients (over 18 years of age), both sexes (male and female), with physical state of handle 1 to 3 , patients electively or urgently scheduled for laparoscopic cholecystectomy, under general anesthesia. The following patients were excluded: patients with known psychiatric disorders, or mental disorders, hearing or motor impairments that incapacitate them to answer questions, or alter the results due to lack of inadequate understanding of indications or questions, patients with chronic upload pain treatment, benzodiazepines or immunomodulators, patients with chronic treatment with anxiolytics, benzodiazepines, patients consuming antiepileptic drugs. ASA 4 patients or older or in a state of shock of any kind. Patients with established or already diagnosed with diabetic neuropathy. The elimination criteria include the following: absence or lack of any part of the clinical record, lack of authorization with the signature of the patient or the relative responsible for the informed consent of anesthesia, or refusal by the patient. Under the following protocol: after a pre-anesthetic evaluation, any doubts they expressed about the study were clarified.

\subsection{Two Groups of Patients will be Assigned to this Study:}

- Group 1: Fentanyl was administered intravenously for anesthetic induction at doses of 3-5 mcg/kg, with subsequent maintenance doses of 50 to $100 \mathrm{mcg}$ bolus every 30 minutes until the end of the anesthetic procedure.

- Group 2: Sufentanil was administered at an induction dose of 10 to $15 \mathrm{mcg}$ in bolus, with subsequent maintenance doses of 10 mcg in bolus every 50 minutes until the end of the anesthetic procedure.

The patients who accepted their admission to the study, after the surgical act, were admitted to the post-anesthetic care unit and were indicated non-invasive monitoring consisting of blood pressure, pulse oximetry, and electrocardiogram in DII and V5, in addition to supplemental oxygen.

In both groups, the degree of residual sedation was recorded, the presence of pain or not was also measured according to the analogous pain scale (VAS), upon admission to the postanesthetic care unit.The pain scale was measured and recorded upon admission to the UCPA, at the time of the post-anesthetic, at 12 hours and the subsequent 24 hours. The patients remained in the recovery area for an average of about two hours after the surgery and were discharged in the absence of pain when they did not show deterioration in alertness and were able to maintain the autonomy of their actions and their spontaneous mobilization.

In order to assess the hemodynamic response to pain, hemodynamic variables of blood pressure and heart rate were evaluated by non-invasive monitoring on arrival of the patient to the recovery room, one hour later, at 12 and 24 hours after the postoperative period. All parameters were recorded on data collection sheet throughout the follow-up: An X2 analysis was carried out to find differences between the proportions of men and women in each group, as well as the percentage of patients who presented pain, the intensity of this by means of the VAS scale and if they needed rescue analgesia. Based on the presence of pain, the VAS scale was measured by the Friedman test. The student's t-test was used to compare demographic variables. Statistical comparison of blood pressure averages (systolic and diastolic), heart rate, was performed with two-way analysis of variance (ANOVA) in which the group (fentanyl and sufentanil) and the intervention phase (baseline, one hour, 12 hours and 24 hours postoperatively) within the model. The value of $\mathrm{p}<0.05$ was statistically significant. 
The information was processed in the SPPSS program, version 19.0, IBM Illinois, USA, 2010. The results are expressed in graphs and tables.

\section{Results}

A total of 50 patients were included, 25 in each group. The minimum age was 17 years, and the maximum was 82 years, with an average of 45.4 years. The analog visual scale of pain from admission to recovery was reported with a mode of 1 in 37 patients (74\%) (Table 1).The mean blood pressure at admission had an average of $86.78 \mathrm{mmHg}$, a minimum of $63 \mathrm{mmHg}$, and a maximum of $110 \mathrm{mmHg}$. The average heart rate was $73 \mathrm{bpm}$, with a minimum of 48 and a maximum of 115. At the time, they had a MAP of $86.68 \mathrm{mmHg}$, a minimum of $70 \mathrm{mmHg}$, and a maximum of $110 \mathrm{mmHg}$. The hourly heart rate Table1: Initial VAS (visual analog scale) had an average of $69 \mathrm{bpm}$, minimum 50, and a maximum of $90 \mathrm{bpm}$. At $12 \mathrm{~h}$ PAM of $85.48 \mathrm{mmHg}$, a minimum of $73 \mathrm{mmHg}$ and a maximum of $110 \mathrm{mmHg}$. The heart rate at $12 \mathrm{~h}$ had an average of $72 \mathrm{bpm}$, a minimum of 56, and a maximum of $85 \mathrm{bpm}$. At $24 \mathrm{~h}$, the PAM was $85.86 \mathrm{mmHg}$, minimum $73 \mathrm{mmHg}$, and a maximum of $113 \mathrm{mmHg}$.

The heart rate at $24 \mathrm{~h}$ had an average of $72 \mathrm{bpm}$, a minimum of $60 \mathrm{bpm}$, and a maximum of 84 bpm. The period in which greater administration of rescue NSAIDs was required was at 12 hours with a total of 8 patients, the average being one patient at other times. However, there was no statistically significant difference between both groups in pain perception or administration of NSAIDs $(\mathrm{p}<0.05)$.

\begin{tabular}{|l|l|l|l|}
\hline $\begin{array}{l}\text { VAS reaching recovery } \\
\text { room }\end{array}$ & \multicolumn{1}{|c|}{$\begin{array}{c}\text { Total frequency } \\
\mathbf{n}=(\mathbf{5 0})(\boldsymbol{\%})\end{array}$} & \multicolumn{1}{|c|}{ Gentaniln=(25) (\%) } & \multicolumn{1}{c|}{ Sufentaniln=(25)(\%) } \\
\cline { 3 - 4 } & $37(74)$ & $20(40)$ & $17(34)$ \\
\hline 1 & $10(20)$ & $2(4)$ & $8(16)$ \\
\hline 3 & $2(4)$ & $2(4)$ & 0 \\
\hline 6 & $1(2)$ & $1(2)$ & 0 \\
\hline
\end{tabular}

Table2: $\operatorname{VAS} 1 \mathrm{~h}$

\begin{tabular}{|l|l|l|l|}
\hline \multirow{2}{*}{ VAS (1 hour) } & \multicolumn{1}{|c|}{$\begin{array}{c}\text { Total frequency } \\
\mathbf{n = ( 5 0 ) ( \% )}\end{array}$} & \multicolumn{1}{c|}{ Group } \\
\cline { 3 - 4 } & \multicolumn{1}{|c|}{ Fentaniln= (25)(\%) } & Sufentaniln=(25)(\%) \\
\hline 1 & $16(32)$ & $11(22)$ & $5(10)$ \\
\hline 2 & $18(36)$ & $7(14)$ & $11(22)$ \\
\hline 3 & $10(20)$ & $5(10)$ & $5(10)$ \\
\hline 4 & $4(8)$ & $2(4)$ & $2(4)$ \\
\hline 5 & $1(2)$ & 0 & $1(2)$ \\
\hline 6 & $1(2)$ & 0 & $1(2)$ \\
\hline
\end{tabular}

Table3: $E V A$ 12h

\begin{tabular}{|l|l|l|l|}
\hline VAS (12 hours) & \multicolumn{1}{|c|}{$\begin{array}{c}\text { Frequency } \\
\text { n= (50)(\%) }\end{array}$} & \multicolumn{2}{c|}{ Group } \\
\cline { 3 - 4 } & & $12(24)$ & \multicolumn{1}{c|}{ Sentaniln=(25)(\%) } \\
\hline 1 & $20(40)$ & $13(26)$ & $8(16)$ \\
\hline 2 & $27(54)$ & 0 & $14(28)$ \\
\hline 4 & $2(4)$ & 0 & $2(4)$ \\
\hline
\end{tabular}

Table4: $\operatorname{VAS} 24 \mathrm{~h}$

\begin{tabular}{|c|c|c|c|}
\hline \multirow[t]{2}{*}{ VAS (24 hours) } & \multirow{2}{*}{$\begin{array}{c}\text { Total frequency } \\
n=(25)(\%)\end{array}$} & \multicolumn{2}{|c|}{ Group } \\
\hline & & Fentaniln $=(25)(\%)$ & Sufentaniln $=(25)(\%)$ \\
\hline 1 & $25(50)$ & $13(26)$ & $12(24)$ \\
\hline 2 & $18(36)$ & $10(20)$ & $8(16)$ \\
\hline 3 & $1(2)$ & 0 & $1(2)$ \\
\hline 4 & $1(2)$ & 0 & $1(2)$ \\
\hline 5 & $3(6)$ & $1(2)$ & $2(4)$ \\
\hline 6 & $2(4)$ & $1(2)$ & $1(2)$ \\
\hline
\end{tabular}

\section{DISCUSSION}

Postoperative pain in patients who have undergone laparoscopic cholecystectomy varies from mild to moderate, even severe pain, according to known pain scales, which complicates the speedy recovery of the patient overcoming the benefit of a patient. Minimallyinvasive surgerysurgical factors include abdominal distention from insufflated gas,surgical time, metabolic response to trauma, 
and the surgeon's own ability to reduce these factors.The therapy used by anesthesiologists for the induction and maintenance of anesthesia include fentanyl, an opioid 100 times more potent than morphine, with a time and analgesic potency less than sufentanil, which shows a duration of analgesia up to 60 minutes, with lower doses and decreasing the metabolic response to trauma, providing better postoperative analgesia with faster recovery and decreasing rescue doses with NSAIDs in the postoperative period.

This pain variability was appreciated in the present study, since a pain differential (VAS) can be seen between the fentanyl group and the sufentanil group; it is appreciated that the group treated with sufentanil pain is similar in the first 12 and 24 hours; the presence of pain was assessed according to the VAS scale on three scales; In the present study a difference between the fentanyl group and the sufentanil group is not significant, since even with the presence of pain in the surgical sites the pain was referred to as minor in both groups, from the moment the patient leaves the operating room, until 12 to 24 hours after the patient's discharge. Due to the hemodynamic response of the patient to pain, if there is variability between the fentanyl group and the sufentanil group, however it is only statistically significant in systolic blood pressure, this situation can be affected by the establishment of pneumoperitoneum in the abdominal cavity with hemodynamic response that it generates in the patient. Therefore, we conclude that the use of sufentanil in the transanesthetic will offer greater analgesia in the postoperative period in patients who undergo cholecystectomy by laparoscopic technique compared to the patients in which it was used in the fentanyl trans-anesthetic.

\section{CONCLUSION}

The analgesia obtained by the use of sufentanil in the postoperative period of laparoscopic cholecystectomy has excellent results, with adequate pain control and VAS $<3$, with rescue analgesia requirements at 12 hours similar to those required with the use of fentanyl, without showing a significant difference in these parameters nor the others evaluated. Further studies are required with a sample of patients that allow us to perform a statistical analysis that allows us to elucidate the significance of the analgesic differences between both drugs.

\section{REFERENCES}

[1] Aguilera L. Importancia de los parámetros farmacocinéticos y farmacodinámicosen las interacciones farmacológicas, Rev Esp Anestesiol Reanim 2003:50:251-2.

[2] Kazama T. Reduction by fentanyl of the CP50 values of propofol and hemodynamic responses to various noxious stimuli. Anesthesiology 1997; 87:213-217.

[3] Kazama T, et al. The pharmacodynamic interaction between propofolan fentanyl with respect to the suppression of somatic or hemodynamic responses to skin incision, peritoneum incision and abdominal wall retraction. Anesthesiology 1998; 89:894-906.

[4] Muñoz-Cuevas JH. Anestesiabasadaen analgesia. Rev Mex de Anestesiología2007 ; 3 0 Supl 1):S180-S184.

[5] Rivera R, Antognioni JF. Perioperative drug therapy in elderly patients. Anesthesiology 2009; 110:1176-1181.

[6] White $P$, Kehlet $H$. The role of the anesthesiologist in fast-track surgery: From multimodal analgesia to perioperative medical care. Anesth-Analg 2007; 104:1380-1396.

[7] Hughes M, Glass P. Context-sensitive half-tima in multicompartment pharmacokinetic models for intravenous anesthetic drugs. Anesthesiology 1992; 76:334-341.

[8] Peng P, Sandler A. A review of the use of fentanyl analgesia in the management of acute pain in adults. Anesthesiology 1999; 90:576599.

[9] Philbin DM. Fentanyl a sufentanyl anaesthesia revisted: How much is enough? Anesthesiology 1990; 75:5-11.

[10] Trescot. Opioid pharmacology. Pain Physician 2008: Opioid Special Issue:

[11] 11: S133-S153 • ISSN 1533-3159. 11. Smith. Combination opioid analgesics. Pain physician 2008; 11:201-214 • ISSN 1533-3159.

Citation: Luis Angel Medina Andrade MD, Carlos barrientos Anderwald MD, et.al, Comparison of PostOperative Pain after Laparoscopic Cholecystectomy with the Use of Fentanilo or Sufentanilo. ARC Journal of Surgery.2019; 5(3):7-11. DOI: http://dx.doi.org/10.20431/2455-572X.0503003

Copyright: (C) 2019 Authors. This is an open-access article distributed under the terms of the Creative Commons Attribution License, which permits unrestricted use, distribution, and reproduction in any medium, provided the original author and source are credited. 